\title{
Magnetic resonance spectroscopy reveals that activated monocytes contribute to neuronal injury in SIV neuroAIDS
}

Kenneth Williams, 1,2 Susan Westmoreland,1,3 Jane Greco, 1,4 Eva Ratai, 1,4 Margaret Lentz,1,4 Woong-Ki Kim,1,2 Robert A. Fuller, ${ }^{1,4}$ John P. Kim,1,4 Patrick Autissier, ${ }^{1,2}$ Prahbat K. Sehgal,1,3 Raymond F. Schinazi, ${ }^{5}$ Norbert Bischofberger, 6 Michael Piatak Jr., 7 Jeffrey D. Lifson,7 Eliezer Masliah, ${ }^{8}$ and R. Gilberto González ${ }^{1,4}$

\begin{abstract}
${ }^{1}$ Harvard Medical School, Boston, Massachusetts, USA. ${ }^{2}$ Division of Viral Pathogenesis, Beth Israel Deaconess Medical Center, Boston, Massachusetts, USA. ${ }^{3}$ New England Primate Research Center, Southborough, Massachusetts, USA. ${ }^{4}$ Neuroradiology Division and Martinos Center for Biomedical Imaging, Massachusetts General Hospital, Charlestown, Massachusetts, USA. ${ }^{5}$ Laboratory of Biochemical Pharmacology, Department of Pediatrics, Emory University School of Medicine/Veterans Affairs Medical Center, Atlanta, Georgia, USA. ${ }^{6}$ Gilead Sciences, Foster City, California, USA ${ }^{7}$ AIDS Vaccine Program, Science Applications International Corporation Frederick Inc., National Cancer Institute at Frederick, Frederick, Maryland, USA. ${ }^{8}$ Neurosciences Department, UCSD, La Jolla, California, USA.
\end{abstract}

\begin{abstract}
Difficulties in understanding the mechanisms of HIV neuropathogenesis include the inability to study dynamic processes of infection, cumulative effects of the virus, and contributing host immune responses. We used ${ }^{1} \mathrm{H}$ magnetic resonance spectroscopy and studied monocyte activation and progression of CNS neuronal injury in a CD8 lymphocyte depletion model of neuroAIDS in SIV-infected rhesus macaque monkeys. We found early, consistent neuronal injury coincident with viremia and SIV infection/activation of monocyte subsets and sought to define the role of plasma virus and monocytes in contributing to CNS disease. Antiretroviral therapy with essentially non-CNS-penetrating agents resulted in slightly decreased levels of plasma virus, a significant reduction in the number of activated and infected monocytes, and rapid, near-complete reversal of neuronal injury. Robust macrophage accumulation and productive virus replication were found in brains of infected and CD8 lymphocyte-depleted animals, but no detectable virus and few scattered infiltrating macrophages were observed in CD8 lymphocyte-depleted animals compared with animals not receiving antiretroviruses that were sacrificed at the same time after infection. These results underscore the role of activated monocytes and monocyte infection outside of the brain in driving CNS disease.
\end{abstract}

\section{Introduction}

Nearly one-third of HIV-infected individuals develop neurological symptoms ranging from minor cognitive impairment to severe dementia. Neurological deficits are related to neuronal injury and loss; however, the mechanisms of injury are poorly understood. Because the virus does not directly infect neurons, indirect mechanisms are likely operative (1). Observations in HIV-infected humans and SIV-infected animals underscore the role of the immune system in contributing to CNS disease (2-5). Expansion of monocyte subsets, some of which are activated, correlates with the incidence of HIV-associated dementia (HAD) and other CNS diseases without known viral etiology (6-11). Emerging evidence in rodents and humans points to monocyte subsets including $\mathrm{CD} 14^{+} \mathrm{CD} 16^{-}$cells that are actively recruited to inflammatory sites and CD $14^{\text {low }} \mathrm{CD} 16^{+}$cells that traffic to noninflamed tissues (12). Studies of cytokine production and viral infection suggest differential activation of monocyte populations as well

Nonstandard abbreviations used: CART, combination antiretroviral therapy; Cho, choline; $\mathrm{Cr}$, creatine; CSF, cerebrospinal fluid; HAART, highly active antiretroviral therapy; HAD, HIV-associated dementia; MAP-2, microtubule-associated protein 2; MI, myoinositol; MNGC, multinucleated giant cell; MRS, magnetic resonance spectroscopy; NAA, $N$-acetylaspartate; PMPA, (R)-9-(2-phosphonylmethoxypropyl)adenine; RCV, racemic $\beta-2^{\prime}, 3^{\prime}$-dideoxy-5-fluoro-3'-thiacytidine; SIVE, SIV encephalitis.

Conflict of interest: The authors have declared that no conflict of interest exists.

Citation for this article: J. Clin. Invest. 115:2534-2545 (2005).

doi:10.1172/JCI22953. as differential susceptibility to infection (12-14). Activated CD8 ${ }^{+}$ T lymphocytes in blood, cerebrospinal fluid (CSF), and the CNS parenchyma are detected in infected individuals and animals at sites where they are thought to contribute to neurophysiological abnormalities and perhaps control monocyte accumulation in the CNS (3,15-17). In addition, levels of chemoattractants/ chemokines regulating monocytes/macrophage and $\mathrm{T}$ cell traffic are elevated in the CSF with HIV and SIV infection and correlate with the incidence of $\operatorname{HAD}(18,19)$. These observations support the putative role of activated monocytes and $\mathrm{CD}^{+} \mathrm{T}$ lymphocytes in regulating HIV-induced CNS disease (20).

Obstacles to precisely defining immune system contribution to CNS disease include the inability to assay neuronal injury longitudinally and the sporadic nature and low incidence of HAD. Not knowing when and how long individuals are infected adds another level of uncertainty. Advances in noninvasive neuroimaging using ${ }^{1} \mathrm{H}$ magnetic resonance spectroscopy (MRS) allow for the detection of brain abnormalities prior to the onset of neurological symptoms. Such studies can also measure reversal of abnormalities with antiretroviral therapy (21-25).

SIV, like HIV, infects CD4 ${ }^{+} \mathrm{T}$ lymphocytes, blood monocytes/ macrophages, and brain macrophages (26-28). The SIV-infected macaque model of neuroAIDS best recapitulates HIV neuropathogenesis; but similar to the situation in HIV-infected humans, the low percentage $(25 \%)$ of animals developing SIV encephalitis (SIVE) and the prolonged progression (1-3 years) to the devel- 

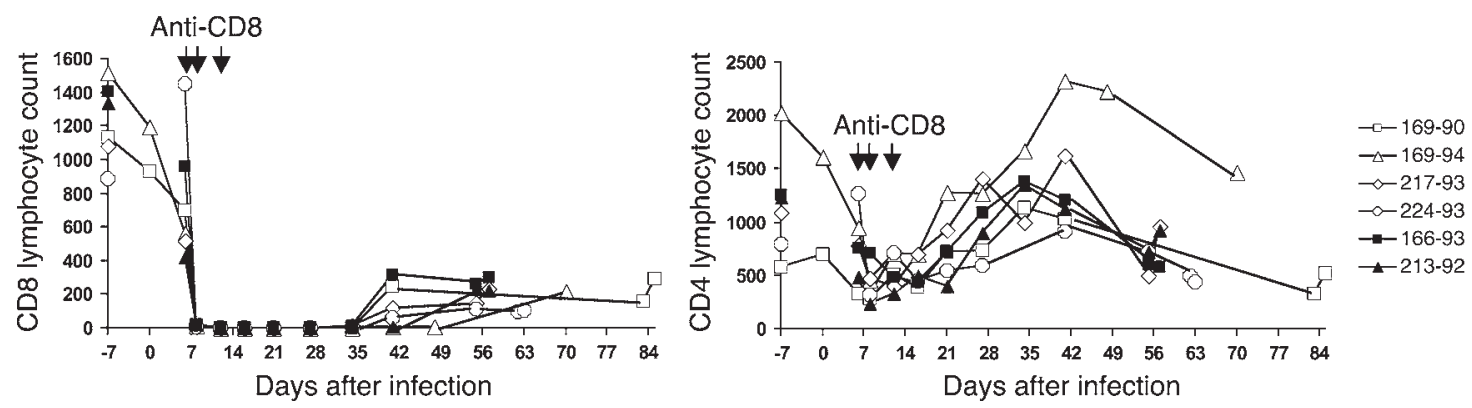

\section{Figure 1}

Depletion of CD8 lymphocytes in SIV-infected rhesus macaques by administration of mAb cM-T807. Absolute number of CD3+CD4+ and CD3+CD8+ T lymphocytes from SIVmac251-infected, CD8 lymphocyte-depleted rhesus macaques. Data presented are for 6 SIV-infected, CD8 lymphocyte-depleted animals. Open symbols represent 4 animals that developed AIDS with SIVE. Filled symbols represent animals that received CART beginning on day 28 after infection. Day 0 represents the time of SIVmac251 infection. All animals were persistently CD8+ $T$ lymphocyte depleted (>28 days).

opment of AIDS somewhat limit its usefulness (29). Recently, 2 accelerated macaque models that have rapid disease progression and high incidence of SIVE have been reported (30-33). One uses 2 viruses that result in CD4 ${ }^{+} \mathrm{T}$ lymphocyte depletion and highly efficient replication in CNS macrophages $(30,34)$. The other uses mAb-mediated depletion of CD8 lymphocytes, which results in accumulation of monocytes/macrophages in the CNS early after infection, rapid disease progression, and severe SIVE (31-33). Both models underscore a role of the peripheral immune system in controlling the rate and severity of CNS disease progression $(2,16)$.

Here we report marked and consistent neuronal injury, as assessed by decreased $N$-acetylaspartate (NAA) levels detected by in vivo ${ }^{1} \mathrm{H}$ MRS, in SIV-infected and CD8 lymphocyte-depleted animals. Such injury occurs over a short time and is highly reproducible in persistently CD8 lymphocyte-depleted animals. Histopathologic examination revealed significant accumulation in CNS of perivascular macrophages, SIV protein, multinucleated giant cells (MNGCs), glial cell activation, and neuronal injury. Flow cytometric analysis demonstrated an expansion of a population of activated monocytes with viremia coinciding with decreased NAA that subsides and then reemerges with the onset of AIDS and SIVE. Quantitative PCR of FACS-sorted monocytes demonstrated a population of activated $\mathrm{CD} 14^{\text {low }} \mathrm{CD} 16^{\text {high }}$ cells that were consistently SIV DNA positive. Additional animals underwent combination antiretroviral therapy (CART) immediately after significant decreases in NAA/creatine (NAA/Cr) were measured by MRS. In CART animals, a rapid reversal of the decrease in NAA/Cr was found by 2 weeks after treatment, and the NAA/Cr ratios further returned to near preinfection levels by 4 weeks. CART led to a nominal decrease in plasma virus (100- to 1,000 -fold), but significant inhibition of activated, SIV-infected monocytes was observed in non-CART animals that developed AIDS in the same period. Significantly, CART resulted in decreased monocyte infection by SIV. These data demonstrate the utility of a CD8 lymphocyte depletion model of neuroAIDS and MRS to study CNS pathogenesis and neuronal injury and underscore the role of the peripheral immune system and activated monocytes in contributing to CNS disease. FACS sorting and PCR analysis show that activated CD14 ${ }^{\text {low }}$ CD $16^{\text {high }}$ monocytes immunophenotypically similar to CNS perivascular macrophages are a probable cellular reservoir for SIV DNA and represent a "Trojan Horse" cell that can potentially carry virus to the CNS.

\section{Results}

These studies were performed in 2 parts. In the first series of experiments, we studied rhesus macaques that were SIV infected and CD8 lymphocyte depleted. In this series, MRS, PCR analysis for virus, flow cytometry, and FACS sorting for monocyte populations were performed for up to 8 weeks; animals were then euthanized, and histopathology assays were performed. In the second series, animals were SIV infected and CD8 lymphocyte depleted and subjected to the same assays described above, except these animals were treated with CART beginning at 28 days after infection so that the effects of decreased viral load and monocyte infection on neuronal injury could be studied.

SIV infection and CD8 depletion induce CNS neuronal injury and encephalitis. Six adult rhesus macaques were inoculated with SIVmac251 and CD8 lymphocyte depleted by administration of a CD8 lymphocyte-depleting antibody 6,8 , and 12 days after infection. Flow cytometry, MRI, and MRS were used to study peripheral monocyte activation and infection, plasma viral load, and neuronal injury during infection and AIDS. Flow cytometric analysis of peripheral blood and biopsied lymph nodes confirmed that all animals were persistently CD8 ${ }^{+} \mathrm{T}$ lymphocyte depleted (at least 28 days) (31) (Figure 1). Histopathological examination of biopsied lymph nodes did not show evidence of any pathology resulting from antibody treatment, consistent with previous studies $(31,32)$. Previous control studies of CD8 lymphocyte depletion without viral infection had shown that lymphoid tissues do not exhibit evidence of pathology $(31,32)$. The number of $\mathrm{CD}^{+} \mathrm{T}$ lymphocytes initially increased with $\mathrm{CD}^{+} \mathrm{T}$ lymphocyte depletion, beginning at day 7 , and then decreased with the reemergence of $\mathrm{CD} 8^{+} \mathrm{T}$ lymphocytes between days 35 and 62 . The absolute number of $\mathrm{CD}^{+} \mathrm{T}$ lymphocytes did not return to predepletion levels (Figure 1).

${ }^{1} \mathrm{H}$ magnetic resonance spectra of frontal cortex, basal ganglia, and centrum semiovale were obtained, and NAA/Cr, choline/Cr (Cho/Cr), and myoinositol/Cr (MI/Cr) ratios calculated. Significant decreases in levels of the neuronal marker NAA, indicative of neuronal injury, were noted in all 3 brain regions of all animals following SIV infection and CD8 lymphocyte depletion. Decreases in NAA/Cr from preinfection time points to the onset of AIDS were easily detected, remarkably even by visual inspection (Figure 2 , top panel). The decreases in NAA/Cr were more robust, with less animal-to-animal variation, than those observed in studies of SIVmac251-infected animals that were not CD8 lymphocyte depleted 



(35). Analysis of the first 4 SIVmac251-infected, CD8 lymphocytedepleted animals showed a striking decrease in NAA/Cr at several time points between SIV inoculation and onset of AIDS (Figure 2 , bottom panel). Linear regression analysis revealed an inverse relationship between time of infection and NAA/Cr in the frontal cortex, basal ganglia, and the white matter. The $19 \%$ decrease in $\mathrm{NAA} / \mathrm{Cr}$ in frontal gray matter and $14 \%$ decrease in white matter were revealed to be statistically significant $(P=0.02$ and $P=0.04$, respectively) by 2 -tailed paired Student's $t$ tests. In contrast to the decreases in NAA/Cr, Cho/Cr and MI/Cr did not change significantly over the course of infection (data not shown). Review of the MRI images revealed no abnormality in any animal at any time before or after infection.

The 4 SIVmac251-infected, CD8 lymphocyte-depleted animals described above were euthanized when moribund with AIDS, having survival times of $57,63,70$, and 85 days after infection (mean, 69 days after infection). Plasma virus levels in all animals peaked by 7-28 days after infection and remained elevated at later time points (Table 1). Microscopic, histopathological, and immunohistochemical examinations showed that all animals had SIVE, as defined by the presence of infiltrating perivascular mac-

\section{Figure 2}

SIV infection and CD8 lymphocyte depletion results in rapid and robust neuronal injury. Upper panel: In vivo ${ }^{1} \mathrm{H}$ magnetic resonance spectra from frontal cortex of a rhesus macaque. Before SIV inoculation (left) and 10 weeks after SIV infection and CD8 depletion. Indicated on the spectrum are the metabolites utilized for the study, which included NAA, $\mathrm{Cho}, \mathrm{Cr}$ and $\mathrm{MI}$. The hatched line demonstrates a decline in the intensity of the NAA resonance that is observed 10 weeks after infection when the spectra are normalized to the $\mathrm{Cr}$ resonance (dotted line). Lower panel: Changes in NAA/Cr as a function of time after infection in SIV-infected, CD8 lymphocyte-depleted animals. Data are from 4 SIV-infected, CD8 lymphocyte-depleted animals. Three of 4 animals were scanned twice before infection, so there are 7 data points at time 0 . All 4 animals were scanned at 2 weeks after infection. Three animals were scanned at 21 days and 3 were scanned at 40 days after infection. Thereafter, the animals were scanned at lower frequency. The measurements were derived from in vivo ${ }^{1} \mathrm{H}$ MR spectra acquired from $1.5 \times 1.5 \times 1.5 \mathrm{~cm}^{3}$ voxels localized to the frontal lobe, centrum semiovale and basal ganglia. A strong linear relationship between the time of infection and the NAA/Cr ratio was present for frontal cortex within the frontal lobe $(r=-0.70 ; P=0.0001)$ (left), basal ganglia $(r=-0.57 ; P=0.006)$ (center), and centrum semiovale white matter $(r=-0.68 ; P=0.0003)$ (right).

rophages, MNGCs, and SIV-p27-positive, productively infected macrophages. The histopathology of these animals was similar to that of the most severe cases of SIVE we have observed in non-CD8 lymphocyte-depleted animals. Numerous cuffs of perivascular and inflammatory macrophages and MNGCs were found in virtually all brain sections examined. All sections had multiple lesions containing SIV-p27-positive, productively infected macrophages, damaged and injured neurons, white matter loss, and vacuolation (Figure 3). It is impossible to determine the exact timing of CNS pathologic changes, but neuronal injury was indicated by decreased NAA/Cr as early as 2 weeks after infection, occurring with an increased percentage of activated and infected blood monocytes (described below).

Postmortem neuronal assays confirm neuronal injury detected by MRS. Postmortem analysis of NAA/Cr by ex vivo MRS and quantitative immunohistochemical measurements of synaptophysin and microtubule-associated protein 2 (MAP-2) were performed to verify neuronal injury in the SIV-infected, CD8-depleted macaques. Frontal cortex samples from the 4 CD8 lymphocyte-depleted animals that were euthanized when they developed AIDS were evaluated and compared with frontal cortex samples from 4 control,

Table 1

Summary of SIV-infected, CD8-depleted rhesus macaques used in this study

$\begin{array}{lcc}\text { Animal no. } & \begin{array}{c}\text { Duration of } \\ \text { infection (d) }\end{array} & \begin{array}{c}\text { Auration of } \\ \text { CD8 depletion (d) }\end{array} \\ 169-90 & 85 & 26 \\ 169-94 & 70 & 40 \\ 217-93 & 57 & 26 \\ 224-93 & 63 & 33 \\ 166-93 & 57 & 26 \\ 213-92 & 57 & 33\end{array}$

$\begin{array}{crcc}\text { CART } & \begin{array}{c}\text { Plasma viral load (RNA copies/mI) } \\ \text { Peak }\end{array} & \begin{array}{c}\mathbf{3 4} \text { days } \\ \text { after infection }\end{array} & \text { Histopathology } \\ & 18 \times 10^{6} & 64 \times 10^{6} & \text { SIVE } \\ \text { None } & 5 \times 10^{6} & 48 \times 10^{6} & \text { SIVE } \\ \text { None } & 69 \times 10^{6} & 50 \times 10^{6} & \text { SIVE } \\ \text { None } & 28 \times 10^{6} & \text { n.d. } & \text { SIVE } \\ \text { None } & 32 \times 10^{6} & 8.6 \times 10^{6} & \text { P.V. infiltrates } \\ \text { Start 28 days after infection } & 24 \times 10^{6} & 16 \times 10^{6} & \text { Scattered inflammatory cells }\end{array}$

ANon-CART animals with AIDS were moribund with disease at the time of necropsy; CART animals without AIDS were healthy at the time of sacrifice. BPlasma viral load determined by real-time PCR showing peak value of data collected earlier than 28 days after infection and data collected at 34 days after infection, which was the next time point tested. n.d., not determined; P.V. infiltrates, perivascular infiltrates. 

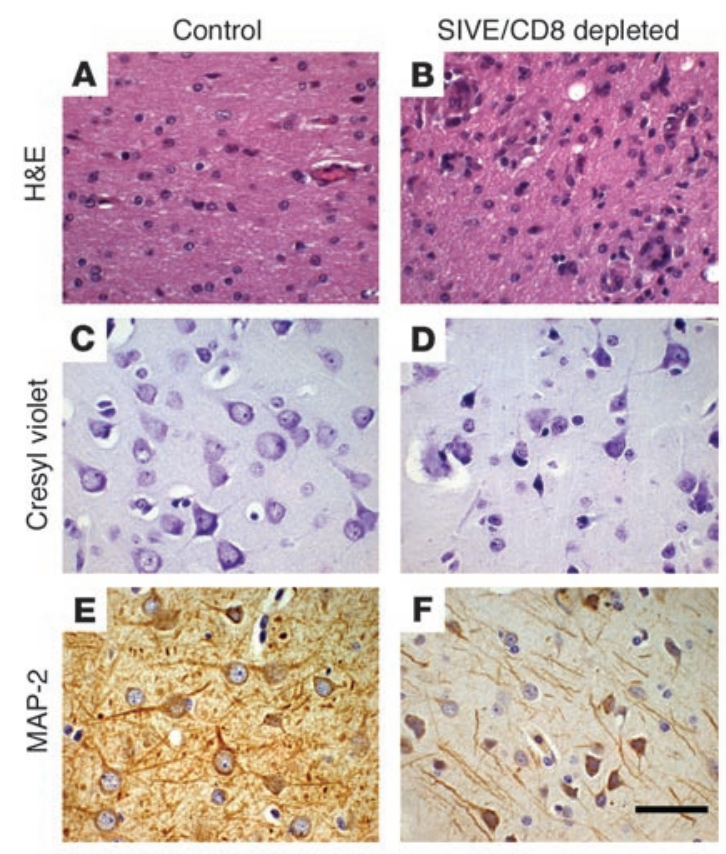

uninfected macaques. The in vivo NAA/Cr ratio in the frontal cortex of animals in the experimental group before SIV infection was the same as that of the control group (control, $1.29 \pm 0.03$; experimental, $1.29 \pm 0.04$ ). Ex vivo ${ }^{1} \mathrm{H}$ MRS measurements of brain extracts from both groups of animals demonstrated a lower NAA/ $\mathrm{Cr}$ ratio $(P<0.0005)$ in the SIV-infected, CD8-depleted animals (Figure 4). Quantitative immunohistochemical analysis revealed lower levels of synaptophysin $(P<0.004)$ in the SIV-infected, CD8 lymphocyte-depleted animals and a trend toward a decrease in MAP-2 $(P<0.09)$ (Figure 4). The observations of reduced levels of synaptic (synaptophysin) and dendritic (MAP-2) neuronal proteins were consistent with increased neuronal injury as shown by diminished NAA/Cr in vivo and ex vivo and by pathologic examination.

The degree of monocyte activation and infection correlates with CNS neuronal injury. Flow cytometry was used to measure changes in the percentage of CD14 monocytes and monocyte subpopulations and to sort populations for analysis of SIV RNA and DNA (Figure 5). These studies showed an increase in the percentage of $\mathrm{CD} 14^{+}$ monocytes that coexpressed CD16. The percentage of these cells in blood initially increased 7-14 days after infection coincident with initial decreases in CNS NAA/Cr (Figure 6A). Increases in the absolute number or the percentage of $\mathrm{CD} 14^{+}$and $\mathrm{CD} 14^{+} \mathrm{CD} 16^{+}$ monocytes have been reported in HIV-infected humans and SIV-infected monkeys $(8,36-38)$. Such increases in CD14- and CD16-positive monocyte populations are considered predictive of the incidence of $\operatorname{HAD}(6,8)$, although longitudinal analyses of their expansion and direct correlation with neuronal injury have not been performed. In addition to the increased percentage of CD14 $4^{+}$blood monocytes that coexpressed CD16, we also found an increase in the percentage of blood monocytes characterized by low CD14 and high CD16 expression $\left(\mathrm{CD} 14^{\text {low } C D 16 ~} 6^{\text {high }}\right.$ ) (Figure 5). When analyzing either monocyte population, we found an increase in the percentage of cells after infection and then another increase prior to or with the onset of AIDS. To establish the timing and contribution of monocyte infection to CNS disease, we FACS sorted subsets of monocytes with varying levels of CD14 and

\section{Figure 3}

Histopathological examination reveals inflammation, MNGCs, and neuronal injury in SIV-infected and CD8 lymphocyte-depleted monkeys. Photomicrograph of representative H\&E (A and B), cresyl violet (C and D), and MAP-2 (E and F) micrographs demonstrate inflammation and degenerative changes in cortical neurons of CD8-depleted rhesus compared with uninfected controls. The H\&E micrograph demonstrates extensive perivascular infiltrates and large cells with multiple nuclei in the CD8-depleted rhesus (B), while no evidence of infiltrates is seen in the uninfected control (A). The cresyl violet micrograph of the CD8-depleted animal (D) reveals severe cortical neuronal damage characterized by pyknotic nuclei as well as morphologic alterations of shrunken and angular cortical neurons compared with that of the control (C). Further evidence of neuronal injury is demonstrated by markedly decreased immunohistochemical expression of MAP-2 in neuronal processes in CD8-depleted rhesus (F) compared with uninfected control (E). Scale bar: 25

CD16 using gates represented in Figure 5B. These subsets were selected because they are discreet and nonoverlapping populations that could be separated by FACS sorting. Quantitative PCR revealed early peaks in both RNA and DNA levels between 7 and 21 days after infection. This peak decreased after 21 days and then increased a second time with or prior to the development of AIDS (Figure 6, B and C). While neither subset exclusively harbored SIV RNA or DNA, the CD14 $4^{\text {low }} \mathrm{CD} 16^{\text {high }}$ population was consistently SIV DNA positive, above the detection limit of the assay, in all animals. These observations, along with the earlier suggestion that $\mathrm{CD} 14^{\text {low }} \mathrm{CD} 16^{+}$monocytes also traffic to noninflamed tissues $(12$, 39) underscore the possibility that these cells function as a cellular reservoir of SIV DNA.

The number of plasma virions per milliliter in CD8 lymphocytedepleted animals peaked 7-14 days after infection and remained elevated. Interestingly, this peak level of plasma virus corresponded with the initial decrease in NAA/Cr in the frontal cortex, basal ganglia, and white matter in all 4 animals, which continued to decrease as a function of time after infection (Figure 7A). In contrast to

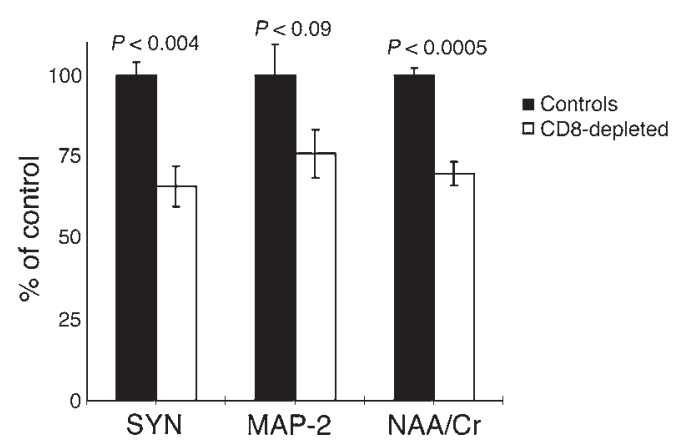

\section{Figure 4}

Neuronal injury in the frontal cortex of SIV-infected, CD8 lymphocytedepleted rhesus macaques demonstrated by decreased synaptophysin and MAP-2 protein expression and decreased NAA/Cr analyzed in ex vivo tissues. Shown are measurements of synaptophysin (SYN), MAP-2, and NAA/Cr in the frontal cortex tissues from controls (black bars) and SIV infected, CD8 lymphocyte-depleted monkeys (white bars). The values are normalized to those for controls, which were considered to be $100 \%$. Error bars represent SEM. $P$ values determined by Student's $t$ test indicated significant or nearly significant differences between the control versus SIV-infected and CD8 lymphocyte-depleted monkeys. 

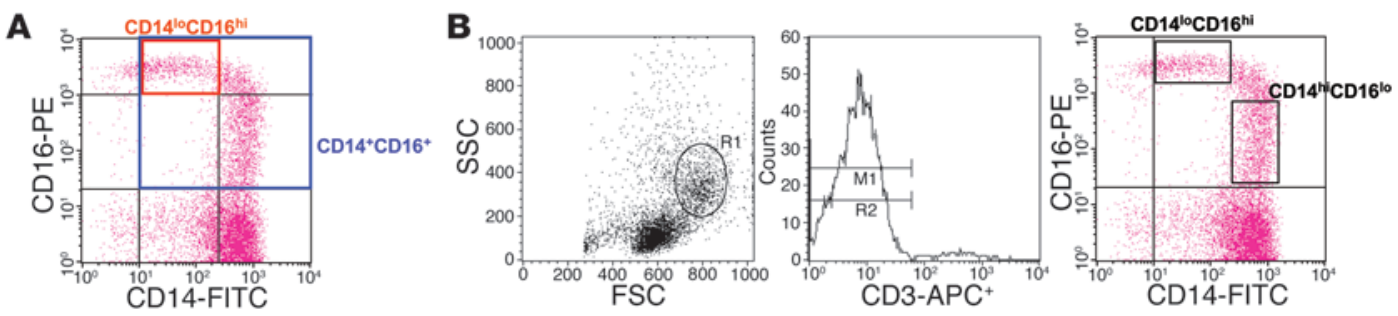

\section{Figure 5}

Analysis and acquisition gates for activated monocytes following SIV infection and CD8 lymphocyte depletion. (A) Representative flow cytometric analysis gates for activated CD14-positive monocytes that coexpressed CD16 (blue box) and CD14low and CD16 high monocytes (red box). (B) FACS-sorted CD14high CD16 low and CD14lowCD16 high monocyte populations from SIV-infected, CD8 lymphocyte-depleted rhesus macaques. Peripheral monocytes were initially identified based on forward scatter-versus-side scatter (FSC-versus-SSC) profiles of PBMCs (left panel). Contaminating CD3-APC+ T lymphocytes were gated out of the monocyte population (middle panel). CD14 ${ }^{\text {high }} \mathrm{CD} 16^{\text {low }}$ and CD14 low $C D 16^{\text {high }}$ monocyte acquisition gates were set (right panel), and $5 \times 10^{4}$ to $3 \times 10^{5}$ cells per monocyte population were sorted.

the level of plasma virus, which peaked early after infection and remained elevated, the percentage of CD14-positive and CD16positive monocytes increased twice: initially with peak viremia and then with AIDS (Figure 6). These observations suggest that plasma virus and/or activated monocytes contribute to neuronal injury.

CART diminishes subsequent monocyte infection and activation. To further study the role of plasma virus and/or activated monocytes contributing to neuronal injury, we initiated CART on 2 SIV-infected, CD8 lymphocyte-depleted animals at day 28 after infection. As in the previous experiment, these animals were persistently $\mathrm{CD}^{+} \mathrm{T}$ lymphocyte depleted (for more than 28 days) (Figure 1). Plasma virus in these animals dropped 100- to 1,000-fold immediately following (R)-9-(2-phosphonylmethoxypropyl) adenine (PMPA) and racemic $\beta-2$ ', $3^{\prime}$-dideoxy-5-fluoro-3'-thiacytidine (RCV) treatment on day 28 after infection (Figure 7A). SIV RNA and DNA levels also decreased in the CSF (data not shown). Paralleling changes in plasma virus levels, SIV RNA and DNA levels decreased in the CD14and CD16-positive monocyte populations after initiation of CART (Figure 7, B and C). The percentage of CD14 monocytes coexpressing CD16 and activated CD $14^{\text {low }} \mathrm{CD} 16^{\text {high }}$ monocytes was increased during primary infection, prior to initiation of CART (Figure 8). However, unlike the non-CART animals that had a second increase

\section{Figure 6}

Expansion of monocyte populations following SIV infection and CD8 lymphocyte depletion and analysis of monocyte-associated SIV RNA and DNA. (A) The percentage of monocytes that coexpress CD16 was assayed as a function of time after infection. Two populations of activated monocytes were assessed: $\mathrm{CD} 14^{+}$monocytes that coexpressed CD16 $\left(C D 14^{+} C D 16^{+}\right)$and CD14 low CD16 ${ }^{\text {high }}$ monocytes. Peaks in the percentage of both populations were observed between 7 and 14 days after infection. A second increase in the percentage of both populations was observed prior to or with the development of AIDS. ${ }^{* *} P<0.05$ and ${ }^{*} P<0.1$ vs. day 0; paired Student's $t$ test. (B) SIV RNA was assessed in FACS-sorted populations of CD14 $4^{\text {high }}$ CD16 low and CD14low CD16 high monocytes. In both populations, there was an initial peak in the level of SIV RNA between 7 and 14 days after infection, followed by a decline and a subsequent increase prior to or coincident with the development of AIDS. (C) SIV DNA was assessed in FACS-sorted populations of CD14 high $C D 16^{\text {low }}$ and CD14 low CD16 high monocytes. In both populations, there was a peak in the level of SIV DNA 7-14 days after infection and another peak with the development of AIDS. The CD14low CD16 high population was consistently SIV DNA positive. The hatched line represents the lower detection limit of the PCR assay. in the percentage of CD14 and CD16 monocytes, CART animals did not (Figure 8). More important, we did not detect subsequent increases in monocyte-associated SIV RNA or DNA levels in CART animals, though, again, the $\mathrm{CD} 14^{\text {low }} \mathrm{CD} 16^{\text {high }}$ population was unequivocally identified as SIV DNA positive (Figure 8).
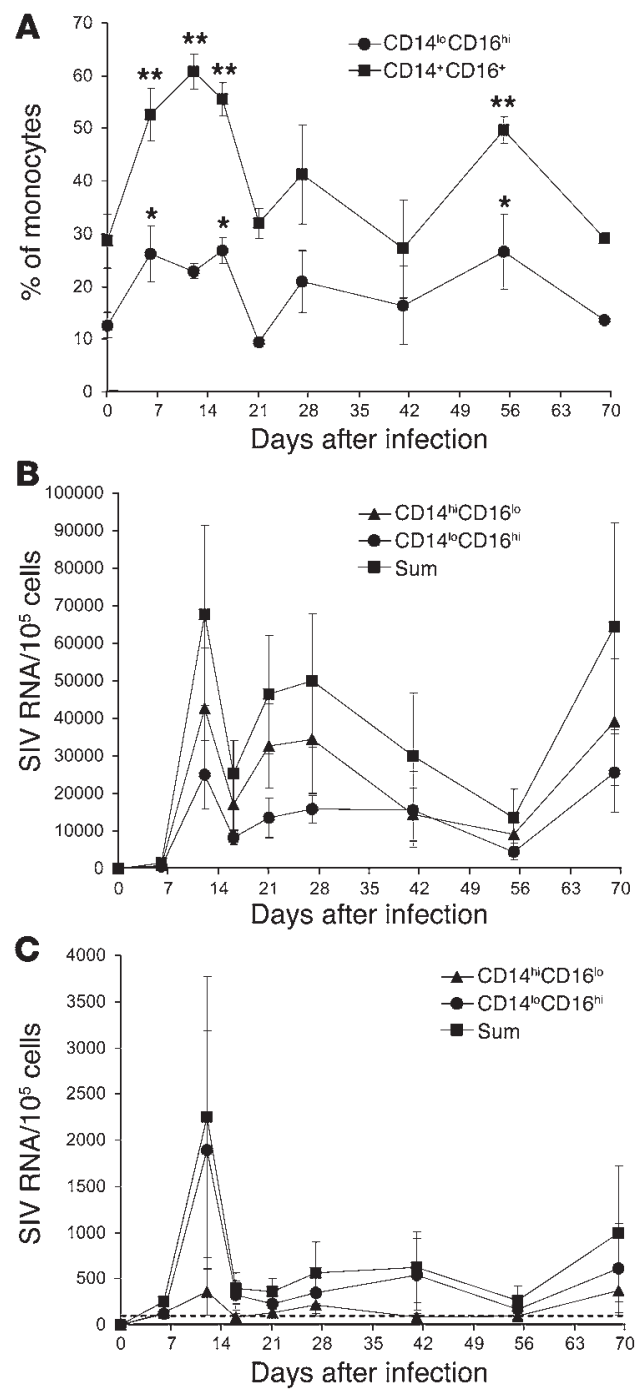

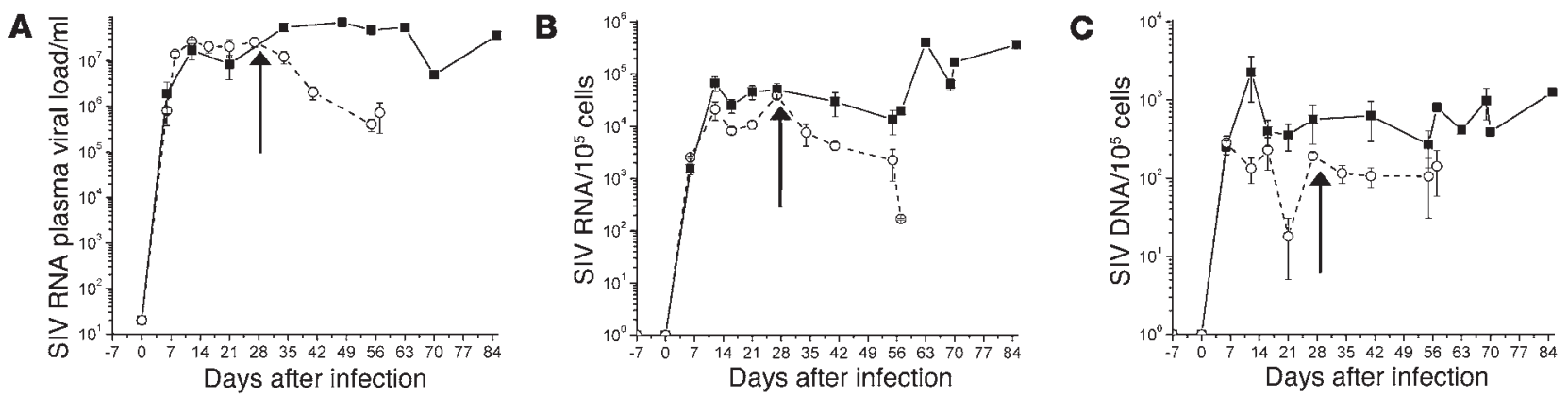

Figure 7

Plasma virus and monocyte-associated SIV RNA and DNA in SIV-infected, CD8 lymphocyte-depleted animals with and without CART. Comparisons were made between SIV-infected, CD8 lymphocyte-depleted animals with (open symbols) and without (filled symbols) CART. Quantitative, real-time PCR analysis demonstrated a decrease in SIV RNA in plasma and cell-associated SIV RNA and DNA in animals that received CART (A). Plasma virion RNA decreased 100- to 1,000-fold following CART that was initiated on day 28 after infection (arrow). (B) The level of monocyteassociated SIV RNA in the total blood monocyte population was decreased in CART-treated animals, which paralleled changes in plasma RNA. (C) The level of monocyte-associated SIV DNA decreased following CART, similar to decreases in plasma and cell-associated RNA levels.

Neuronal injury in SIV neuropathogenesis is rapidly reversed with CART. MRS showed that NAA/Cr decreased in both animals following CD8 depletion and SIV infection, prior to initiation of CART. At 28 days after infection, NAA/Cr ratios decreased to $89 \%$ and $81 \%$ of preinfection levels (Figure 9). Directly after MRS at day 28 after infection, CART commenced. After 2 weeks of CART, MRS revealed a reversal of the decrease in NAA/Cr in both animals (Figure 9). After 4 weeks of antiretroviral therapy, NAA/Cr completely recovered in one animal and increased from $81 \%$ to $93 \%$ of normal, preinfection levels in the other. Previous studies in SIV-infected macaques have confirmed that PMPA does not penetrate into the CNS (40). Of the nucleoside analogs, RCV has one of the lowest CNS penetrations (41). HPLC analysis of RCV metabolites in the CSF following treatment showed no penetration into the CSF.

Histopathologic and immunohistochemical examination of CNS tissues from CART animals demonstrated that neither had SIVE, and in fact they had few inflammatory cells. The animal that did not have a complete recovery of NAA/Cr to prescan levels had scattered accumulations of CD68and CD16-positive perivascular macrophages, while the other animal did not (Figure 10). Tissue sections from both animals showed no evidence of SIV-p27, which indicated a lack of detectable

\section{Figure 8}

Percentage of monocytes and monocyteassociated SIV RNA and DNA in SIVinfected, CD8-depleted animals on CART. Similar to SIV-infected, CD8 lymphocytedepleted monkeys, animals on CART (initiated 28 days after infection; arrows) had an increased percentage of activated monocyte populations by 7-14 days after infection. SIV RNA levels peaked between 7 and 28 days after infection, and SIV DNA levels peaked between 7 and 14 days after infection. Unlike non-CART animals, animals on CART did not have a second peak in either activated monocytes or monocyteassociated SIV RNA or DNA levels. productive infection as assessed by immunohistochemistry. We did not assay for SIV DNA or RNA and thus did not assess latent infection. These data are in stark contrast to those for non-CART animals, which had significant decreases in NAA/Cr and severe SIVE at the time of sacrifice. Non-CART animals had MNGCs and easily detectable SIV-p27 viral load in all brain sections examined. It is interesting to note that both the antiretrovirus-treated and nontreated animals were persistently $\mathrm{CD}^{+} \mathrm{T}$ lymphocyte depleted and had no or low absolute numbers of $\mathrm{CD} 8^{+} \mathrm{T}$ cells at death. Overall, these observations suggest that activated monocyte and macrophage accumulation in the CNS are indicators of and likely contributors to CNS neuronal injury.

\section{Discussion}

In this study, we examined CNS neuronal injury in a rhesus macaque model of neuroAIDS. In order to longitudinally assess mechanisms of neuronal injury in vivo during accelerated SIVE development, we used ${ }^{1} \mathrm{H}$ MRS to monitor plasma virus and monocyte activation lev-
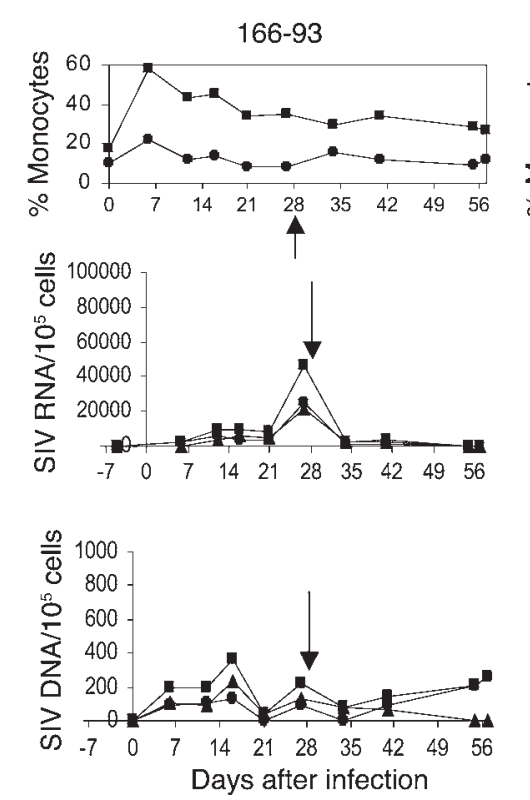
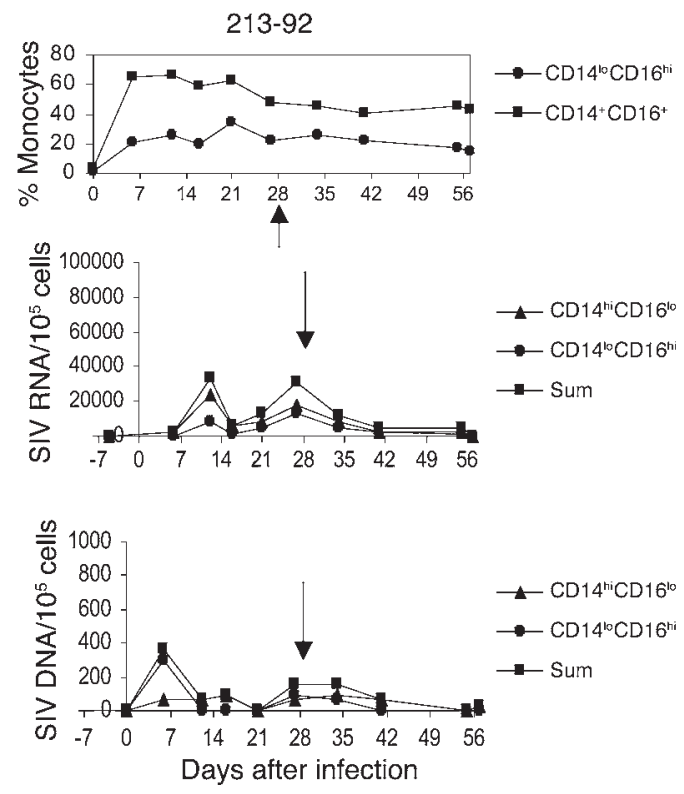


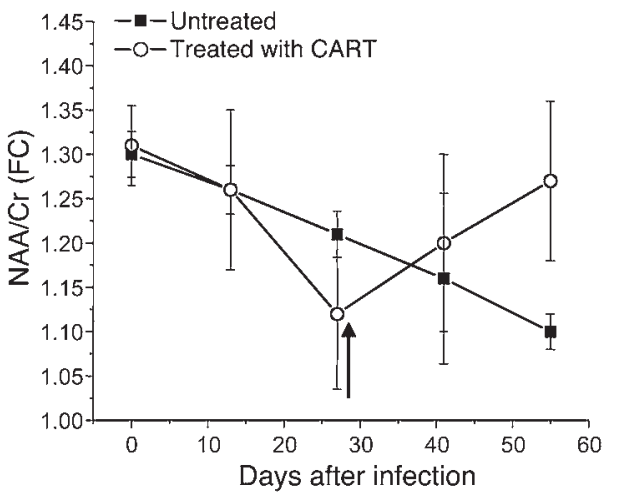

els in SIV-infected, CD8 lymphocyte-depleted macaques. Decreases in NAA/Cr in vivo occurred with initial activation and infection of monocytes in blood and macrophage accumulation; decreased NAA, MAP-2, and synaptophysin levels were observed in the CNS in postmortem assays. CART resulted in a rapid and significant reversal of decreased NAA levels, even though plasma and monocyteassociated SIV DNA and RNA levels decreased modestly. CART animals did not develop SIVE, and they had few CNS lesions and no detectable SIV protein as assessed by immunohistochemistry. These observations point to differences in neuropathology that are attributable to changes in peripheral blood virus levels and, more significantly, activation of peripheral monocytes and accumulation of monocytes/macrophages in the CNS.

We used MRS to monitor neuronal injury in vivo at several time points to study the role of plasma virus and activated and infected monocytes in neuropathology. The role of NAA as a reliable, noninvasive MRS neuronal marker has been confirmed by a large number of published studies $(42,43)$. We have previously reported direct, linear relationships between the number of neurons and NAA/Cr in postmortem Alzheimer and Pick disease brains (35, 42). Moreover, we have recently found that transient changes in NAA/Cr best correlated with changes in synaptophysin levels during acute SIV infection in the macaque (43). ${ }^{1} \mathrm{H}$ MRS has been widely used to study HIV-infected patients, and early studies reported profound decreases

\section{Figure 9}

CART results in the rapid reversal of neuronal injury in SIV-infected, CD8 lymphocyte-depleted monkeys. NAA/Cr ratios in the frontal cortex (FC) of 2 SIV-infected, CD8 lymphocyte-depleted animals decreased to $89 \%$ and $81 \%$ of preinfection levels by 28 days after infection (open circles). Immediately after the MRS analysis on day 28 , CART was initiated. Two weeks following CART, MRS revealed reversal of NAA/Cr in both animals. After 4 weeks of CART, one animal had a complete recovery of $\mathrm{NAA} / \mathrm{Cr}$, while the levels in the other animal increased from $81 \%$ to $93 \%$ of preinfection values. For comparison, NAA/Cr ratios in the frontal lobe of SIV-infected animals and CD8 lymphocyte-depleted animals that were not on CART, as shown in Figure 1, are also presented here (filled squares). in NAA/Cr (24, 44-48); such drops are less dramatic in the current highly active antiretroviral therapy (HAART) era. Improvement in $\mathrm{NAA} / \mathrm{Cr}$, along with neurocognitive improvement, has been reported following treatment with HAART $(22,25)$, which parallels the effect of treatment in the model reported here. Still, a recent multicenter study reported an $8 \%$ decrease in NAA/Cr in the centrum semiovale in patients undergoing HAART compared with controls (49).

Our studies demonstrate an expansion of CD14- and CD16positive monocyte populations that others have described in HIV infection. We have extended these observations, pointing to a role of plasma virus and/or monocyte activation outside the CNS in neuronal injury. These monocytes are similar immunophenotypically and biologically to CNS perivascular macrophages that we and others have demonstrated are a major cell type productively infected by SIV and HIV in the CNS (9, 50-53). Several groups have reported that a unique phenotypic subset of activated monocytes is expanded in the blood of HIV-infected patients $(10,11,54,55)$. Early studies showed an increased frequency of CD14 monocytes that coexpressed CD16 $(10,11)$. Pulliam et al. reported a strong correlation between the incidence of HAD and the percentage of CD14-positive monocytes that coexpress CD16 and/or CD69 (8). The accumulation of perivascular macrophages in the brain as well as of macrophages of a similar immune phenotype in the lung correlates with the histopathology of CNS and lung $(56,57)$.

\section{Figure 10}

CART animals have no evidence of productive SIV infection and minimal inflammatory macrophages in the brain. Immunohistochemical characterization of lesions in SIVmac251-infected CD8-depleted untreated and CD8-depleted PMPA- and RCV-treated rhesus macaques. CD68 (KP1)-immunopositive perivascular macrophages in representative cerebral white matter samples from CD8depleted untreated (A), CD8-depleted treated (B), and uninfected control animals (C). CD16-immunopositive activated perivascular macrophages and microglia in CD8-depleted untreated (D), CD8depleted treated $(\mathbf{E})$, and uninfected control animals (F). SIV-infected cells immunopositive for SIV-p27 in CD8-depleted untreated (G), CD8-depleted treated (H), and uninfected control animals (I). These data demonstrate a significant number of inflammatory macrophages and productive infection of the CNS in CD8 lymphocytedepleted animals. In contrast, there were minimal inflammatory macrophages and no evidence of productive viral replication in CD8 lymphocyte-depleted monkeys that received PMPA and RCV. Data presented here are representative of 4 SIV-infected, CD8 lymphocyte-depleted animals; 2 SIV-infected, CD8 lymphocyte-depleted animals on CART; and 2 noninfected controls.

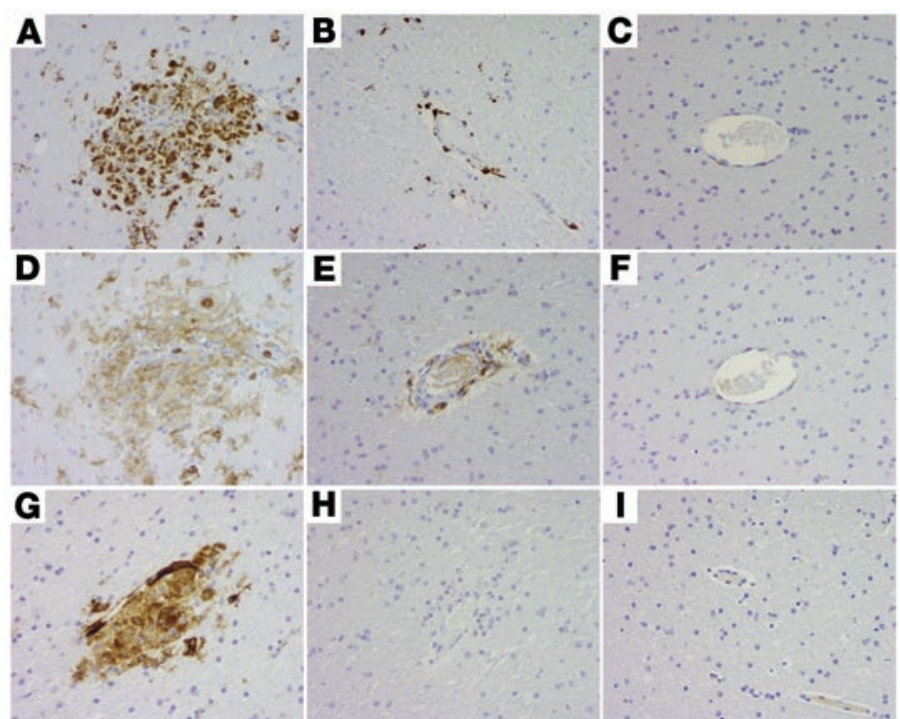


Analysis of monocyte-associated SIV RNA and DNA demonstrated that the expanded population of monocytes, including the CD14 ${ }^{\text {low }}$ CD $16^{\text {high }}$ subset, was SIV infected, which implicates them as a potential cellular reservoir of virus and viral replication, as has been demonstrated in humans $(54,58)$, even patients on HAART (54). Whether these cells are the type that carry virus to the CNS has not been directly addressed in this study. However, studies in rodents and humans have established that perivascular macrophages are continuously repopulated from the bone marrow at a rate that is accelerated with inflammation $(59,60)$.

We have previously shown that SIV-infected and CD8-depleted rhesus macaques, sacrificed 21 days after infection, already have a significant accumulation in the CNS of perivascular macrophages, some of which are already productively infected by SIV (33). This is in contrast to nondepleted animals, sacrificed at the same time point, in which it is extremely difficult to detect productively infected perivascular macrophages. The observation that a high number of macrophages in the CNS correlates with diminished NAA/Cr strongly suggests that activated monocytes that can traffic to the CNS contribute to neuronal injury in AIDS. These data further suggest that viral infection outside the CNS and $\mathrm{CD}^{+} \mathrm{T}$ lymphocytes in part control the number of monocytes and their degree of activation and infection and accumulation in the CNS. CART slightly decreased the plasma virus level, which was sufficient to decrease subsequent monocyte activation and, importantly, decrease monocyte-associated SIV RNA and DNA.

The results of our study using CART are in accordance with a recent report by Fox et al. (40). In these studies, neurophysiologic abnormalities measured during chronic SIV infection were reversed following PMPA treatment. However, Fox et al. did not use MRS and were thus unable to demonstrate a neuronal correlate of their neurophysiology readings (40). Interestingly, in Fox's study, monocyte chemoattractant protein-1 (MCP-1), a chemokine that regulates monocyte traffic to the CNS, was increased in the CSF upon primary infection and when animals developed AIDS. These observations are similar to those in HIV-infected humans, in whom elevated chemokine levels in the CSF correlate with $\operatorname{HAD}(15,18,19)$. In Fox's study, animals treated during chronic infection did not have a second peak in the level of CSF MCP-1. This is similar to what we observed in PMPA- and RCVtreated monkeys, which did not have a second wave of activated $\mathrm{CD}_{14}{ }^{+}$and $\mathrm{CD} 16^{+}$monocytes, decreased NAA/Cr, or macrophage accumulation in the CNS. It has been speculated that the neurological benefits of HAART, reported in previous studies, were due to immune system modulation $(61,62)$. Our observation that macrophage accumulation in the CNS correlates with decreased NAA/Cr parallels observations of macrophage accumulation and paralysis in EAE. In the animal model of multiple sclerosis, macrophage and $\mathrm{T}$ lymphocyte accumulation is rapid, occurring days after active and passive immunization, and coincident with the induction of paralysis. Once inflammation wanes, in a matter of days, macrophages are no longer detected in the CNS, and paralysis resolves. In the case of SIV and HIV, viral infection or loss of $\mathrm{CD}^{+} \mathrm{T}$ lymphocyte immune responses, or both, allow for a continued macrophage accumulation $(3,20,63)$. It is possible that results from the CD8 depletion model represent a compression of the normal time frame seen in non-CD8-depleted animals and HIV-infected humans with CNS disease. In non-CD8-depleted monkeys and humans, the development of AIDS and CNS disease occurs with immune system dysfunction as indicated by loss of
CD4 and CD8 lymphocyte function and dysregulated, activated monocytes/macrophages $(3,64,65)$. Several studies have recently used PMPA and RCV in SIV pathogenesis models (66-70). To date, there are no reports that treatment with either of these agents directly inhibits cellular immune responses. In this regard, the relative numbers of $\mathrm{CD}^{+}$and $\mathrm{CD}^{+} \mathrm{T}$ lymphocytes in our PMPA/ RCV-treated versus nontreated animals were similar, which suggests that there was no effect of drug treatment on the percentage of lymphocytes in the blood.

It is important to note that several studies have suggested a role of immune responses in controlling the development of SIVE and HIV encephalitis $(2,40,71)$. $\mathrm{CD}^{+} \mathrm{T}$ lymphocytes, many of which are potentially SIV antigen specific, have been demonstrated in the CNS of animals early after infection and terminally, where they are thought to play a role in viral containment and also neuronal injury $(17,72)$. Because all of the animals in our study were $\mathrm{CD}^{+} \mathrm{T}$ lymphocyte depleted when brain imaging occurred, it is possible that additional neuronal injury might have occurred with a full CD8 $\mathrm{T}$ cell component. Last, it has been suggested that CD8 lymphocytes regulate the expression of SIV RNA and protein in the CNS of infected animals (34). While such mechanisms likely occur, it is interesting that in the 2 PMPA- and RCV-treated animals, we did not detect SIV-p27 in the CNS, despite the presence of $\mathrm{CD}^{+} \mathrm{T}$ lymphocytes. These observations suggest that in our model, a continuous reseeding of virus from monocytes is required for CNS infection.

The present study used an SIV infection and CD8 lymphocyte depletion protocol in macaques to reproducibly induce CNS injury. Our results show that CART abolishes the expansion of activated monocyte populations and can almost completely reverse neuronal injury in the CNS, although its antiretroviral effect is confined in the periphery. These observations suggest that (a) neuronal injury in this model is reversible and (b) neuronal injury is likely dependent upon systemic viral replication, monocyte activation, or both. It is important to note that the partial inhibition of viral replication in the periphery was sufficient to rescue CNS neurons from injury. Taken together, these observations suggest that the immune system controls the regulation of the development of both AIDS and encephalitis and that activated monocytes, previously recognized as a surrogate marker of HAD, likely drive neuroAIDS progression.

\section{Methods}

SIV inoculation and CD8 depletion. All animals were housed according to the standards of the American Association for Accreditation of Laboratory Animal Care. Investigators abided by the Guide for the Care and Use of Laboratory Animals of the Institute of Laboratory Animal Resources (National Reseach Council). The study was approved by the Massachusetts General Hospital Subcommittee on Research and Animal Care and the Institutional Animal Care and Use Committee of Harvard University. Six rhesus macaques (Macaca mulatta) were inoculated with SIVmac251 (20 ng SIV-p27, i.v.). To achieve rapid disease progression with a high incidence of SIVE, all infected animals were CD8 lymphocyte depleted by treatment with an anti-CD8 antibody cM-T807 administered s.c. $(10 \mathrm{mg} / \mathrm{kg})$ at day 6 after infection and i.v. $(5 \mathrm{mg} / \mathrm{kg})$ at days 8 and 12 after infection (31, 32). This protocol resulted in rapid $\mathrm{CD} 8^{+} \mathrm{T}$ lymphocyte depletion that was transient ( $<21$ days) in approximately $50 \%$ of animals and persistent $(>28$ days) in $50 \%$. More than $95 \%$ of persistently $\mathrm{CD}^{+} \mathrm{T}$ lymphocyte-depleted animals develop AIDS and SIVE (33). The anti-CD8 mAb cM-T807 recognizes the $\mathrm{CD} 8 \alpha$ chain that is present on $\mathrm{CD}^{+} / \mathrm{CD}^{+}$lymphocytes and 
$\mathrm{CD}^{-} / \mathrm{CD}^{+}$NK cells. Accordingly, NK cells are also likely depleted; however, the efficiency and duration of such depletion has not been addressed. For this reason, we refer to CD8 lymphocyte depletion when using the depleting antibody in animals, while the flow cytometry experiments assess $\mathrm{CD}^{+} / \mathrm{CD}^{+} \mathrm{T}$ lymphocyte depletion.

$\mathrm{CD}^{+} \mathrm{T}$ lymphocyte depletion was monitored by flow cytometry prior to antibody treatment and during infection weekly thereafter. Analysis of inguinal lymph nodes biopsied at day 16 after infection confirmed lymphocyte depletion of lymphoid tissues. Flow cytometric analyses were performed with $100-\mu \mathrm{l}$ aliquots of blood or $1 \times 10^{6} \mathrm{lymph}$ node cells incubated with fluorochrome-conjugated antibodies including anti-CD3-APC (clone FN18; BioSource International), anti-CD4-FITC (OKT4; Ortho Diagnostic Systems), anti-CD8-PE (DK25; DakoCytomation), and anti-CD20-PE-Texas Red (B1; Beckman Coulter). Following antibody incubation for 15 minutes at room temperature, cells were washed twice with PBS containing $2 \%$ FBS; erythrocytes were lysed using ImmunoPrep Reagent System (Beckman Coulter); and samples were washed with PBS, resuspended in $2 \%$ formaldehyde in PBS, and analyzed on a FACSCalibur flow cytometer (BD). The absolute number of $\mathrm{CD}^{+} \mathrm{T}$ lymphocytes was determined by multiplying the percentage of $\mathrm{CD}^{+} / \mathrm{CD}^{+} \mathrm{T}$ cells by absolute lymphocyte counts obtained using a T540 Hematology Analyzer (Beckman Coulter).

MRI and MRS. MRI and MRS were performed before and approximately every 2 weeks after SIV inoculation. For this, animals were initially tranquilized with tiletamine $\mathrm{HCl}$, and anesthesia was maintained via continuous propofol infusion. Brain imaging was performed on a clinical 1.5 Tesla General Electric Signa scanner using a linear extremity coil. Neuroimaging consisted of T1-weighted sagittal images, dual-echo, protondensity and T2-weighted axial images. Axial images were used to localize three $1.5 \mathrm{~cm} \times 1.5 \mathrm{~cm} \times 1.5 \mathrm{~cm}$ spectroscopy voxels: one in the frontal lobe with the voxel centered on the interhemispheric fissure; a second in the right or left centrum semiovale; and a third centered on the right or left putamen. On repeat imaging, the animal's head was positioned as in the previous study (73) using 3-plane scout imaging and iterative repositioning with highly reproducible voxel placement. With the exception of a slightly smaller voxel size, the MRS protocol described here is identical to the one employed in multicenter human HIV studies that is characterized by high reproducibility (49). The protocol uses automated PROBE-P spectroscopy package (General Electric), which consists of a point resolved spectroscopy sequence (echo time $[\mathrm{TE}]=35 \mathrm{~ms}$; repetition time $[\mathrm{TR}]=3,000 \mathrm{~ms}$ ) with chemical selective saturation water suppression (74). Instrument stability was confirmed through analysis of MRS data from phantom, which is a $1-\mathrm{L}$ plastic bottle containing known concentrations of NAA, Cr, Cho, and MI, acquired on the same day the animals were scanned. Over 3 years of imaging studies, the standard deviations for the Cho/Cr, NAA/Cr, and $\mathrm{MI} / \mathrm{Cr}$ phantoms were $2.7 \%, 3.0 \%$, and $5.8 \%$, respectively. Regression analysis demonstrated a slope of less than $0.01 \%$ for each metabolite ratio versus time, which demonstrated that there were no detectable changes in metabolite ratios, and confirmed instrument stability over this period.

MR spectra were processed off-line with the SAGE spectral analysis program (General Electric) (74) to determine intensities of the NAA, Cho, MI, and $\mathrm{Cr}$ resonances. Metabolite ratios with $\mathrm{Cr}$ as the denominator were calculated. ANOVA analysis of MRS data for the entire cohort was performed, and the results for the scans taken at 9 and 10 weeks after infection were grouped. Significant differences between the pre- and postinfection values were isolated using the Dunnett test. The values for the last scan for each animal were compared with the preinfection values using a paired Student's $t$ test. $P$ values of less than 0.05 were considered statistically significant. Linear regression analysis was used to determine the relationship between the time of infection and the metabolite values. T1-weighted, proton density, and $\mathrm{T} 2$-weighted images were reviewed by a neuroradiologist to control for structural or signal abnormalities.

CART. To investigate the role of plasma virus and monocyte activation/ infection in CNS neuronal injury, we treated 2 SIV-infected, CD8 lymphocyte-depleted animals with CART beginning 28 days after infection, once we had confirmed by MRS significant decreases in NAA/Cr. CART consisted of treatment with PMPA and RCV $(75,76)$. PMPA is a nucleotide analog that does not penetrate the $\mathrm{CNS}$, and $\mathrm{RCV}$ is a nucleoside analog of a class that has low-to-nondetectable CNS penetration (40, 77-79). PMPA and $\mathrm{RCV}$ were dissolved in water at $30 \mathrm{mg} / \mathrm{ml}$ and the PMPA $\mathrm{pH}$ adjusted to 7.0 with $3 \mathrm{~N} \mathrm{NaOH}$. Animals received daily injections of PMPA (30 mg/ $\mathrm{kg})$ and RCV $(10 \mathrm{mg} / \mathrm{kg})$ s.c. Plasma and CSF specimens taken before and after initiation of CART were stored at $-80^{\circ} \mathrm{C}$, and RCV metabolites were analyzed by HPLC, as previously described (76).

Tissue collection and processing. Four animals were euthanized when they developed AIDS (ranging from 57-85 day after infection). Two animals that underwent CART were euthanized 2 weeks after initiation of treatment. Four noninfected controls were used for ex vivo MRS analysis and histopathology. All animals were anesthetized with ketamine- $\mathrm{HCl}$, euthanized by intravenous pentobarbital overdose, and exsanguinated. CNS tissues were collected in $10 \%$ neutral buffered formalin, embedded in paraffin, and sectioned at $6 \mu \mathrm{m}$.

Postmortem neuronal assays. Quantitative immunohistochemistry on frontal cortex tissues and high-resolution ${ }^{1} \mathrm{H}$ MRS of brain extracts from the same region were used to evaluate the neuronal status of 4 SIV-infected, CD8 lymphocyte-depleted macaques that were not on CART and 4 nonSIV-infected controls at the time of euthanasia. These experimental animals were compared with 4 healthy, noninfected controls.

Ex vivo ${ }^{1} H$ MRS. We performed ex vivo MRS to assess changes in NAA/ $\mathrm{Cr}$ on brain tissues from 4 SIV-infected, CD8 lymphocyte-depleted animals and 4 non-SIV-infected controls to confirm in vivo experiments. For this, brain tissue was extracted using methanol/chloroform as previously described (80) modified for small samples using the FastRNA Green/ Biopulverizing System I (Qbiogene Inc.) and a FastPrep FP 120 cell disrupter (Thermo Electron Corp.). Extracts were dissolved in $\mathrm{D}_{2} \mathrm{O}$, and ${ }^{1} \mathrm{H}$ NMR studies were preformed on a Bruker Avance $600 \mathrm{MHz}$ spectrometer (Bruker Instruments Inc.). A 1-pulse experiment was used with spectral acquisition parameters including a $90^{\circ}$ pulse length of $9 \mu$ s, recycle delays of 20 seconds, a spectral width of $7.2 \mathrm{kHz}, 32,000$ complex points, and 64 scans, which were averaged. All spectra were processed off-line with the Peak Research NMR Software spectral analysis program (PERCH Solution version 2000/1; PERCH Solutions Ltd.).

Quantitative immunohistochemistry. The integrity of neuronal synapses was evaluated with a mAb against synaptophysin (Boehringer Mannheim), and the status of neuronal dendrites was evaluated using a mAb against MAP-2 (Boehringer Mannheim). Synaptophysin is a $38-\mathrm{kd}$ calcium-binding protein localized to synaptic vesicles (81) and has been implicated in synaptic formation or stabilization (82). Synaptophysin is commonly used to assess synaptic density (83-87). MAP-2 is a high-molecular-weight protein that localizes to the dendritic compartment of neurons and is involved in microtubule assembly. Five-micron-thick paraffin sections from the frontal cortex of both control and SIV-infected macaques were immunolabeled as previously described $(84,86,88)$. Levels of synaptophysin and MAP-2 were measured by computer-aided image analysis utilizing the Quantimet $570 \mathrm{C}$ microdensitometer $(84,88,89)$. For this purpose, 3 immunlolabeled sections from each animal were analyzed. The system was first calibrated with a set of filters of various densities, and a total of 10 images at $\times 100$ magnification was obtained for each section. The area of interest (cortical layers 2-5) was delineated with the cursor, and then the optical density 
within that area was determined. The optical density in each image was averaged and expressed as the mean per animal.

Flow cytometry and FACS-sorted monocyte populations. Five to 20 million Ficoll-Hypaque-separated PBMCs isolated from SIV-infected monkeys were stained with FITC-conjugated anti-CD14 (clone M5E2; BD Biosciences Pharmingen), PE-conjugated anti-CD16 (3G8; BD Biosciences - Pharmingen), and APC-conjugated anti-CD3 (FN18; BioSource International). Cell sorting was done using a FACS Vantage (BD) flow cytometer in a Biosafety Level 2 facility. Monocyte populations were acquired using forward-versus-side scatter profiles and an acquisition gate (Figure 5B, left panel), and $\mathrm{CD}^{+} \mathrm{T}$ lymphocytes were excluded by a second acquisition gate (Figure $5 \mathrm{~B}$, middle panel). Monocytes were fractionated based on CD14 and CD16 expression. For this and in order to best separate different populations of cells expressing CD14 and CD16, sorting gates for CD14 high CD $16^{\text {low }}$ and $\mathrm{CD} 14^{\text {low }} \mathrm{CD} 16^{\text {high }}$ monocyte populations were established (Figure $5 \mathrm{~B}$, right panel) $(10,11)$. The percentage of $\mathrm{CD} 14^{+}$monocytes coexpressing $\mathrm{CD} 16$ was assessed (Figure 5A). Sorted cells were washed and rapidly snap-frozen for SIV DNA and RNA analysis, as described below. The purity of all FACSsorted populations was confirmed by flow cytometry and was routinely greater than $95 \%$.

Plasma and CSF SIV RNA. Plasma and CSF SIV RNA were quantified using real-time PCR as previously described (68). SIV virions were pelleted from $0.5 \mathrm{ml}$ of plasma or CSF by centrifugation at $20,000 \mathrm{~g}$ for 1 hour. The fluorescently labeled, real-time PCR probe employed contained a nonfluorescent quencher, BHQ-1 (Biosearch Technologies Inc.), at its 3' end instead of the fluorescent quencher TAMRA (6-carboxy-tetralmethyl-rhodamine). The threshold sensitivity was 100 copy $\mathrm{Eq} / \mathrm{ml}$, with an average interassay coefficient of variation of less than $25 \%$.

Cell-associated SIV RNA and DNA. Total nucleic acids from FACS-sorted cell pellets with defined cell numbers were prepared. Pellets were suspended in $50 \mu \mathrm{l} 3 \mathrm{M}$ guanidine hydrochloride, $50 \mathrm{mM}$ Tris, $\mathrm{pH}$ 7.6, containing $1 \mathrm{mg}$ proteinase $\mathrm{K} / \mathrm{ml}$ and incubated at $37^{\circ} \mathrm{C}$ for 1 hour. Two hundred microliters of $5.5 \mathrm{M}$ (minimum) guanidine thiocyanate, $50 \mathrm{mM}$ Tris, $\mathrm{pH}$ 7.6, $1 \mathrm{mM}$ EDTA containing $600 \mu \mathrm{g}$ glycogen $/ \mathrm{ml}$ were added and samples mixed. Total nucleic acids were recovered by isopropanol precipitation and the pellets washed in 70\% ethanol, air dried, and dissolved in $60 \mu \mathrm{l} \mathrm{RNase-}$ free water. Samples were split into 2 aliquots for separate DNA and RNA real-time PCR assays. For RNA assays, aliquots were treated with DNase, utilizing the DNA-free kit (Ambion Inc.) to remove any SIV DNA-specific signals. To each sample, $6 \mu \mathrm{l}$ of $\times 10$ DNA-free buffer was first added and the samples briefly mixed. Thirty-three microliters was then removed to a separate tube to which $2 \mu \mathrm{l}$ DNaseI and $5 \mu \mathrm{l}$ inactivation reagent were added following the recommendations and protocol of the manufacturer to remove contaminating DNA signal and in preparation of the sample for measurement of SIV RNA equivalents. The reserved $33 \mu \mathrm{l}$ of sample was heated to $100^{\circ} \mathrm{C}$ for 5 minutes and then quenched on ice, in preparation for measurement of SIV DNA equivalents. Quantification of SIV RNA, SIV DNA, and gene sequences for porphobilinogen deaminase (90), a singlecopy genomic sequence used to determine diploid genome equivalents present in the final, prepared DNA sample, was performed as previously described (66). The results were normalized for volume adjustments and are expressed as SIV copy equivalent $/ 10^{5}$ diploid genome equivalents.

Identification of brain macrophages and SIV-infected cells. Routine single-label immunohistochemistry was performed on formalin-fixed sections of frontal cortex using anti-CD16 (1:160; Novocastra) and anti-CD68 (1:400, KP1; DakoCytomation) and for productively infected cells using anti-SIV-p27 (3F7; American Biotech) as previously described (51).

\section{Acknowledgments}

We thank Angela Carville and Elisabeth Ludlage for animal care at the New England Primate Research Center; Eric Broadbent and Ernest Neale for veterinary technical assistance; Elizabeth Curran and Mike O'Connell for pathology support; and Kristen Toohey for photographic assistance. This work was supported in part by grants from the NIH, including National Center for Research Resources (NCRR) RR13214 (to R.G. González) and RR000150 (to. S. Westmoreland); National Institute of Neurological Diseases and Stroke NS34626 (to R.G. González), NS0050041 (to R.G. González and K. Williams), and NS40237 (to K. Williams); and National Institute of Mental Health MH45294 (to E. Masliah). The NEPRC is supported in part through NCRR grant RR00168. The CD8 lymphocyte-depleting mAb used in this work was produced by the National Cell Culture Center with funds provided by NCRR grant RR16001. R.F. Shinazi is supported by Emory University Center for AIDS Research NIH grant 2P30-AI-50409 and the Department of Veterans Affairs. The Center for Functional Imaging Technologies at the Massachusetts General Hospital is supported by NCRR grant RR14075.

Received for publication August 5, 2004, and accepted in revised form June 14, 2005.

Address correspondence to: Kenneth Williams, Viral Pathogenesis, RE113 Beth Israel Deaconess Medical Center, 330 Brookline Avenue, Boston, Massachusetts 02215, USA. Phone: (617) 667-2064; Fax: (617)667-8210; E-mail: Kenneth_Williams@hms.harvard.edu. Or to: R. Gilberto González, Neuroradiology Division, GRB 285, Massachusetts General Hospital, 55 Fruit Street, Boston, Massachusetts 02114, USA. Phone: (617) 726-8628; Fax: (617) 724-3338; E-mail:rggonzalez@partners.org.
1. Kaul, M., Garden, G.A., and Lipton, S.A. 2001 Pathways to neuronal injury and apoptosis in HIVassociated dementia. Nature. 410:988-994.

2. Sopper, S., et al. 1998. Protective role of the virusspecific immune response for development of severe neurologic signs in simian immunodeficiency virus-infected macaques. J. Virol. 72:9940-9947.

3. Williams, K., and Hickey, W.F. 2002. Central nervous system damage, monocytes and macrophages, and neurological disorders in AIDS [review]. Annu. Rev. Neurosci. 25:537-562.

4. Marcondes, M.C., Phillipson, C.A., and Fox, H.S 2003. Distinct clonal repertoire of brain CD8+ cells in simian immunodeficiency virus infection. AIDS. 17:1605-1611.

5. Moniuszko, M., et al. 2003. High frequency of virus-specific CD8+ $\mathrm{T}$ cells in the central nervous system of macaques chronically infected with sim- ian immunodeficiency virus SIVmac251. J. Virol. 77:12346-12351.

6. Pulliam, L., Clarke, J.A., McGrath, M.S., Moore, D., and McGuire, D. 1996. Monokine products as predictors of AIDS dementia. AIDS. 10:1495-1500.

7. Kusdra, L., Rempel, H., Yaffe, K., and Pulliam, L. 2000. Elevation of CD69+ monocyte/macrophages in patients with Alzheimer's disease. Immunobiology. 202:26-33.

8. Pulliam, L., Gascon, R., Stubblebine, M., McGuire, D., and McGrath, M.S. 1997. Unique monocyte subset in patients with AIDS dementia. Lancet. 349:692-695.

9. Gartner, S. 2000. HIV infection and dementia. Science. 287:602-604.

10. Passlick, B., Flieger, D., and Ziegler-Heitbrock, H.W. 1989. Identification and characterization of a novel monocyte subpopulation in human periph- eral blood. Blood. 74:2527-2534.

11. Thieblemont, N., Weiss, L., Sadeghi, H.M., Estcourt, C., and Haeffner-Cavaillon, N. 1995. CD14lowCD16high: a cytokine-producing monocyte subset which expands during human immunodeficiency virus infection. Eur. J. Immunol. 25:3418-3424

12. Geissmann, F., Jung, S., and Littman, D.R. 2003. Blood monocytes consist of two principal subsets with distinct migratory properties. Immunity. 19:71-82.

13. Ancuta, P., et al. 2003. Fractalkine preferentially mediates arrest and migration of CD16+ monocytes. J. Exp. Med. 197:1701-1707.

14. Frankenberger, M., Sternsdorf, T., Pechumer, H., Pforte, A., and Ziegler-Heitbrock, H.W. 1996. Differential cytokine expression in human blood monocyte subpopulations: a polymerase chain 
reaction analysis. Blood. 87:373-377.

15. Kelder, W., McArthur, J.C., Nance-Sproson, T., McClernon, D., and Griffin, D.E. 1998. Betachemokines MCP-1 and RANTES are selectively increased in cerebrospinal fluid of patients with human immunodeficiency virus-associated dementia. Ann. Neurol. 44:831-835.

16. Marcondes, M.C.G., et al. 2001. Highly activated $\mathrm{CD}^{+} \mathrm{T}$ cells in the brain correlate with early central nervous system dysfunction in simian immunodeficiency virus infection. J. Immunol. 167:5429-5438.

17. Jassoy, C., Johnson, R.P., Navia, B.A., Worth, J., and Walker, B.D. 1992. Detection of a vigorous HIV-1specific cytotoxic $\mathrm{T}$ lymphocyte response in cerebrospinal fluid from infected persons with AIDS dementia complex. J. Immunol. 149:3113-3119.

18. Conant, K., et al. 1998. Induction of monocyte chemoattractant protein-1 in HIV-1 Tat-stimulated astrocytes and elevation in AIDS dementia. Proc. Natl. Acad. Sci. U. S. A. 95:3117-3121.

19. Cinque, P., et al. 1998. Elevated cerebrospinal fluid levels of monocyte chemotactic protein-1 correlate with HIV-1 encephalitis and local viral replication. AIDS. 12:1327-1332.

20. Sanchez-Ramon, S., et al. 2003. Low blood CD8+ T-lymphocytes and high circulating monocytes are predictors of HIV-1-associated progressive encephalopathy in children. Pediatrics. 111:E168-E175.

21. Chang, L., et al. 2003. Persistent brain abnormalities in antiretroviral-naive HIV patients 3 months after HAART. Antivir. Ther. 8:17-26.

22. Stankoff, B., et al. 2001. Clinical and spectroscopic improvement in HIV-associated cognitive impairment. Neurology. 56:112-115.

23. Tracey, I., et al. 1998. Increased cerebral blood volume in HIV-positive patients detected by functional MRI. Neurology. 50:1821-1826.

24. Chang, L., Ernst, T., Leonido-Yee, M., Walot, I., and Singer, E. 1999. Cerebral metabolite abnormalities correlate with clinical severity of HIV-1 cognitive motor complex. Neurology. 52:100-108.

25. Chang, L., et al. 1999. Highly active antiretroviral therapy reverses brain metabolite abnormalities in mild HIV dementia. Neurology. 53:782-789.

26. Lackner, A.A. 1994. Pathology of simian immunodeficiency virus induced disease. Curr. Top. Microbiol. Immunol. 188:35-64.

27. Lackner, A.A., Dandekar, S., and Gardner, M.B. 1991. Neurobiology of simian and feline immunodeficiency virus infections. Brain Pathol. 1:201-212.

28. Zink, M.C., Spelman, J.P., Robinson, R.B., and Clements, J.E. 1998. SIV infection of macaques - modeling the progression to AIDS dementia. J. Neurovirol. 4:249-259.

29. Westmoreland, S.V., Halpern, E., and Lackner, A.A 1998. Simian immunodeficiency virus encephalitis in rhesus macaques is associated with rapid disease progression. J. Neurovirol. 4:260-268.

30. Zink, M.C., and Clements, J.E. 2002. A novel simian immunodeficiency virus model that provides insight into mechanisms of human immunodeficiency virus central nervous system disease. J. Neu rovirol. 8(Suppl. 2):42-48.

31. Schmitz, J.E., et al. 1999. Control of viremia in simian immunodeficiency virus infection by $\mathrm{CD} 8+$ lymphocytes. Science. 283:857-860.

32. Schmitz, J.E., et al. 1999. A nonhuman primate model for the selective elimination of CD8+ lymphocytes using a mouse-human chimeric monoclonal antibody. Am. J. Pathol. 154:1923-1932.

33. Williams, K., Alvarez, X., and Lackner, A.A. 2001. Central nervous system perivascular cells are immunoregulatory cells that connect the CNS with the peripheral immune system. Glia. 36:156-164.

34. Clements, J.E., et al. 2002. The central nervous system as a reservoir for simian immunodeficiency virus (SIV): steady-state levels of SIV DNA in brain from acute through asymptomatic infection.
J. Infect. Dis. 186:905-913

35. Greco, J.B., et al. 2002. Magnetic resonance spectroscopy: an in vivo tool for monitoring cerebra injury in SIV-infected macaques. J. Med. Primatol. 31:228-236.

36. Yoshino, N., et al. 2000. Direct detection of apoptotic cells in peripheral blood from highly pathogenic SHIV-inoculated monkey. Biochem. Biophys. Res. Commun. 268:868-874.

37. Israel, Z.R., et al. 1993. Early pathogenesis of disease caused by SIVsmmPBj14 molecular clone 1.9 in macaques. AIDS Res. Hum. Retroviruses. 9:277-286.

38. Otani, I., et al. 1998. Phenotypic changes in peripheral blood monocytes of cynomolgus monkeys acutely infected with simian immunodeficiency virus. AIDS Res. Hum. Retroviruses. 14:1181-1186.

39. Crowe, S., Zhu, T., and Muller, W.A. 2003. The contribution of monocyte infection and trafficking to viral persistence, and maintenance of the viral reservoir in HIV infection. J. Leukoc. Biol. 74:635-641.

40. Fox, H.S., et al. 2000. Antiviral treatment normalizes neurophysiological but not movement abnormalities in simian immunodeficiency virus-infected monkeys. J. Clin. Invest. 106:37-45.

41. Enting, R.H., et al. 1998. Antiretroviral drugs and the central nervous system. AIDS. 12:1941-1955.

42. Cheng, L.L., et al. 1997. Quantitative neuropathology by high resolution magic angle spinning proton magnetic resonance spectroscopy. Proc. Natl. Acad. Sci. U. S. A. 94:6408-6413.

43. Lentz, M.R., et al. 2005. Quantitative neuropathologic correlates of changes in ratio of $\mathrm{N}$-acetylaspartate to creatine in macaque brain. Radiology. 235:461-468.

44. Menon, D.K., et al. 1992. Proton MR spectroscopy of the brain in AIDS dementia complex. J. Comput. Assist. Tomogr. 16:538-542.

45. Chong, W.K., et al. 1993. Proton spectroscopy of the brain in HIV infection: correlation with clinical, immunologic, and MR imaging findings. Radiology. 188:119-124

46. Jarvik, J.G., et al. 1993. Proton MR spectroscopy of HIV-infected patients: characterization of abnormalities with imaging and clinical correlation. Radiology. 186:739-744.

47. Barker, P.B., Lee, R.R., and McArthur, J.C. 1995. AIDS dementia complex: evaluation with proton MR spectroscopic imaging. Radiology. 195:58-64.

48. Tracey, I., et al. 1996. Brain choline-containing compounds are elevated in HIV-positive patients before the onset of AIDS dementia complex: a proton magnetic resonance spectroscopic study. Neurology. 46:783-788

49. Lee, P.L., et al. 2003. A multi-center $1 \mathrm{H}$ MRS study of the AIDS dementia complex: validation and preliminary analysis. J. Magn. Reson. Imaging. 17:625-633.

50. Ulvestad, E., et al. 1994. Human microglial cells have phenotypic and functional characteristics in common with both macrophages and dendritic antigen-presenting cells. J. Leukoc. Biol. 56:732-740.

51. Williams, K.C., et al. 2001. Perivascular macrophages are the primary cell type productively infected by simian immunodeficiency virus in the brains of macaques: implications for the neuropathogenesis of AIDS. J. Exp. Med. 193:905-915.

52. Fingerle, G., et al. 1993. The novel subset of CD14+/CD16+ blood monocytes is expanded in sepsis patients. Blood. 82:3170-3176.

53. Fischer-Smith, T., et al. 2001. CNS invasion by $\mathrm{CD} 14+/ \mathrm{CD} 16+$ peripheral blood-derived monocytes in HIV dementia: perivascular accumulation and reservoir of HIV infection. J. Neurovirol. 7:528-541.

54. Sonza, S., et al. 2001. Monocytes harbour replication-competent, non-latent HIV in patients on highly active antiretroviral therapy. AIDS. 15:17-22.

5. Ziegler-Heitbrock, H.W., et al. 1993. The novel subset of CD14+/CD16+ blood monocytes exhib- its features of tissue macrophages. Eur. J. Immunol. 23:2053-2058.

56. Stevenson, M., and Gendelman, H.E. 1994. Cellular and viral determinants that regulate HIV-1 infection in macrophages. J. Lenkoc. Biol. 56:278-288.

57. Williams, K., et al. 2001. Proliferating cellular nuclear antigen (PCNA) expression as a marker of perivascular macrophages in SIV encephalitis. Am. J. Pathol. 161:575-585.

58. Zhu, T., et al. 2002. Evidence for human immunodeficiency virus type 1 replication in vivo in CD14+ monocytes and its potential role as a source of virus in patients on highly active antiretroviral therapy. J. Virol. 76:707-716.

59. Hickey, W.F., and Kimura, H. 1988. Perivascular microglial cells of the CNS are bone marrow-derived and present antigen in vivo. Science. 239:290-292.

60. Lassmann, H., and Hickey, W.F. 1993. Radiation bone marrow chimeras as a tool to study microglia turnover in normal brain and inflammation. Clin. Neuropathol. 12:284-285.

61. Ferrando, S., et al. 1998. Highly active antiretroviral treatment in HIV infection: benefits for neuropsychological function. AIDS. 12:F65-F70.

62. Sacktor, N.C., et al. 1999. Combination antiretroviral therapy improves psychomotor speed performance in HIV-seropositive homosexual men. Multicenter AIDS Cohort Study (MACS). Neurology. 52:1640-1647.

63. Resino, S., et al. 2003. CD8+ T-cell numbers predict the response to antiviral therapy in HIV-1-infected children. Pediatr. Res. 53:309-312.

64. Rosenberg, E.S., et al. 1997. Vigorous HIV-1-specific CD4+ T cell responses associated with control of viremia. Science. 278:1447-1450.

65. Rosenberg, E.S., et al. 2000. Immune control of HIV-1 after early treatment of acute infection. Nature. 407:523-526.

66. Lifson, J.D., et al. 2003. Transient early postinoculation anti-retroviral treatment facilitates controlled infection with sparing of CD4+ T cells in gut-associated lymphoid tissues in SIVmac239infected rhesus macaques, but not resistance to rechallenge. J. Med. Primatol. 32:201-210.

67. Murry, J.P., et al. 2003. Reversion of the M184V mutation in simian immunodeficiency virus reverse transcriptase is selected by tenofovir, even in the presence of lamivudine. J. Virol. 77:1120-1130.

68. Lifson, J.D., et al. 2001. Role of CD8(+) lymphocytes in control of simian immunodeficiency virus infection and resistance to rechallenge after transient early antiretroviral treatment. J. Virol. 75:10187-10199

69. Van Rompay, K.K., et al. 1998. Administration of 9-[2-(phosphonomethoxy)propyl]adenine (PMPA) for prevention of perinatal simian immunodeficiency virus infection in rhesus macaques. AIDS Res. Hum. Retroviruses. 14:761-773.

70. Van Rompay, K.K., et al. 2004. CD8+-cell-mediated suppression of virulent simian immunodeficiency virus during tenofovir treatment. J. Virol. 78:5324-5337.

71. Kim, W.K., et al. 2004. Identification of T lymphocytes in simian immunodeficiency virus encephalitis: distribution of CD8+ T cells in association with central nervous system vessels and virus. J. Neurovirol. 10:315-325.

72. von Herrath, M., Oldstone, M.B., and Fox, H.S. 1995. Simian immunodeficiency virus (SIV)-specific CTL in cerebrospinal fluid and brains of SIV-infected rhesus macaques. J. Immunol. 154:5582-5589.

73. Greco, J.B., et al. 2004. In vivo $1 \mathrm{H}$ MRS of brain injury and repair during acute SIV infection in the macaque model of neuroAIDS. Magn. Reson. Med. 51:1108-1114.

74. Webb, P.G., et al. 1994. Automated single-voxel proton MRS: technical development and multisite 
verification. Magn. Reson. Med. 31:365-373.

75. Tsai, C.C., et al. 1995. Prevention of SIV infection in macaques by (R)-9-(2-phosphonylmethoxyprop yl)adenine. Science. 270:1197-1199.

76. Schinazi, R.F., et al. 1992. Pharmacokinetics and metabolism of racemic 2',3'-dideoxy-5-fluoro-3'thiacytidine in rhesus monkeys. Antimicrob. Agents Chemother. 36:2432-2438.

77. Clifford, D.B., and Simpson, D. 1998. Targeting HIV therapy for the brain. HIV: advances in research and therapy. 8:10-17.

78. Brinkman, K., Kroon, F., Hugen, P.W., and Burger, D.M. 1998. Therapeutic concentrations of indinavir in cerebrospinal fluid of HIV-1-infected patients [letter]. AIDS. 12:537.

79. Haworth, S.J., Christofalo, B., Anderson, R.D., and Dunkle, L.M. 1998. A single-dose study to assess the penetration of stavudine into human cerebrospinal fluid in adults. J. Acquir. Immune Defic. Syndr Hum. Retrovirol. 17:235-238.
80. Tracey, I., et al. 1997. ${ }^{1} \mathrm{H}$-magnetic resonance spectroscopy reveals neuronal injury in a simian immunodeficiency virus macaque model. J. Acquir. Immune Defic. Syndr. Hum. Retrovirol. 15:21-27.

81. Navone, F., et al. 1986. Protein p38: an integral membrane protein specific for small vesicles of neurons and neuroendocrine cells. J. Cell Biol. 103:2511-2527.

82. Tarsa, L., and Goda, Y. 2002. Synaptophysin regulates activity-dependent synapse formation in cultured hippocampal neurons. Proc. Natl. Acad. Sci. U. S. A. 99:1012-1016.

83. Masliah, E., Terry, R.D., DeTeresa, R.M., and Hansen, L.A. 1989. Immunohistochemical quantification of the synapse-related protein synaptophysin in Alzheimer disease. Neurosci. Lett. 103:234-239.

84. Masliah, E., et al. 1992. Spectrum of human immunodeficiency virus-associated neocortical damage. Ann. Neurol. 32:321-329.

85. Wiley, C.A., et al. 1991. Neocortical damage during
HIV infection. Ann. Neurol. 29:651-657.

86. Masliah, E., et al. 1992. Cortical dendritic pathology in human immunodeficiency virus encephalitis. Lab. Invest. 66:285-291.

87. Eastwood, S.L., Burnet, P.W., McDonald, B., Clinton, J., and Harrison, P.J. 1994. Synaptophysin gene expression in human brain: a quantitative in situ hybridization and immunocytochemical study. Neuroscience. 59:881-892.

88. Gonzalez, R.G., et al. 2000. Early brain injury in the SIV-macaque model of AIDS. AIDS. 14:2841-2849.

89. Masliah, E., Ge, N., Achim, C.L., Hansen, L.A., and Wiley, C.A. 1992. Selective neuronal vulnerability in HIV encephalitis. J. Neuropathol. Exp. Neurol. 51:585-593.

90. Rossio, J.L., et al. 1998. Inactivation of human immunodeficiency virus type 1 infectivity with preservation of conformational and functional integrity of virion surface proteins. J. Virol. 72:7992-8001. 